\title{
Analisis Kepuasaan Pelanggan Terhadap Kualitas Pelayanan $M y$ Rise Dengan Metode Service Quality Dan Improvement Gap Analysis
}

\author{
Andy Kurniawan ${ }^{1}$, Said Salim Dahda ${ }^{2}$, Mohammad Jufriyanto ${ }^{3}$ \\ Teknik Industri, Teknik, Universitas Muhammdiyah Gresik, Sumatera 101 \\ GKB, Gresik 61121 \\ andykurnia619@gmail.com
}

\begin{abstract}
ABSTRAK
My Rise merupakan layanan internet service provider yang dikelolah oleh PT. Jinde Grup Indonesia berlokasi di Gresik dan sudah menjangkau beberapa kecamatan. Kualitas pelayanan yang diberikan oleh perusahaan diperlukan untuk menarik keputusan pembelian atau mencapai tingkat kepuasaan pelanggan. Untuk mengetahui kepuasaan pelanggan berada di level mana, maka dibutuhkan peningkatan teknik untuk menganalisa tingkat kepuasaan pelanggan. Dengan metode Servqual dapat dilakukan perhitungan antara rata-rata kinerja dan harapan pelayanan untuk tiap dimensi Servqual, seperti Tangible, Assurance, Reability, dan Empathy. Dari kuesioner oleh 167 responden didapatkan hasil bahwa kualitas pelayanan PT. Jinde Grup Indonesia saat ini perlu dilakukan perbaikan. Atribut yang perlu untuk dilakukan perbaikan berdasarkan modete IGA yaitu garansi, penampilan petugas, daya tanggap petugas, kemudahan dalam pelayanan, pemberian ganti rugi, layanan sesuai dengan kebutuhan, informasi layanan baru, kantor yang nyaman, serta kecepatanan dan keramahan petugas melayani pelanggan.
\end{abstract}

Kata kunci : Improvement Gap Analysis, My Rise, Service Quality, PT. Jinde Grup Indonesia

\begin{abstract}
My Rise is an internet service provider which is managed by PT. Jinde Group Indonesia is located in Gresik and has reached several sub-districts. The quality of service provided by the company is needed to attract purchase decisions or achieve customer satisfaction levels. To find out which level of customer satisfaction is, it is necessary to improve techniques to analyze the level of customer satisfaction. With the Servqual method, it is possible to calculate the average performance and service expectations for each Servqual dimension, such as Tangible, Assurance, Reability, and Empathy. From the questionnaire by 167 respondents, it was found that the service quality of PT. Jinde Group Indonesia currently needs improvement. Attributes that need to be repaired based on the IGA mode are warranty, appearance of officers, responsiveness of officers, ease of service, compensation, service according to needs, new service information, comfortable office, and the speed and friendliness of officers serving customers
\end{abstract}

.Keywords : Improvement Gap Analysis, My Rise, Service Quality, PT. Jinde Group Indonesia

\section{Jejak Artikel}

Upload artikel : 1 Desember 2021

Revisi : 15 Desember 2021

Publish : 31 Januari 2022 


\section{PENDAHULUAN}

My Rise merupakan nama produk layanan internet service provider yang dikelola oleh PT. Jinde Grup Indonesia yang lokasi di Gresik dan sudah menjangkau beberapa kecamatan yang ada di Kabupaten Gresik. Tujuan dari bisnis ini adalah untuk menyediakan layanan internet yang terjangkau kepada semua lapisan masyarakat. Jumlah pelanggan PT. Jinde Grup Indonesia sampai akhir Februari 2021 sekitar 3000 pelanggan yang mencakup area Kecamatan Cerme, Kecamatan Benjeng, Kecamatan Balongpanggang dan Kecamatan Menganti. Dikarenakan PT. Jinde Grup Indonesia masih perusahaan baru yang belum seluruhnya menggunakan kabel fiber untuk jaringan internet yang diberikan maka beberapa pelanggan masih mengalami internet yang tidak stabil membuat pengaduan ke kantor PT. Jinde Grup Indonesia.

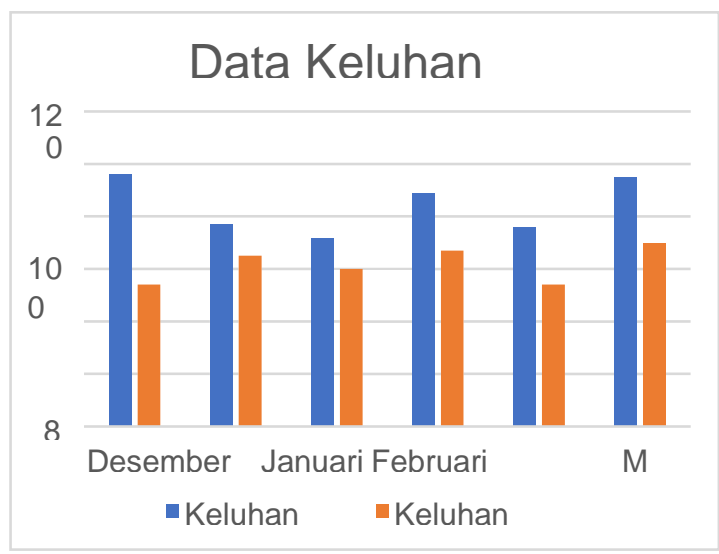

Gambar 1. Data Keluhan Pelanggan

Dari data di atas dapat diketahui bahwa banyaknnya keluhan dari pelanggan sehingga perlu mengatahui kualitas pelayanan yang telah diberikan perusahaan. Kepuasan pelanggan akan tercapai apabila kualitas pelayanan yang diberikan sesuai dengan kebutuhannya. Kepuasan pelanggan merupakan hal yang sangat penting guna menciptakan kualitas terbaik untuk konsumen sendiri. Namun untuk memahami kualitas pelayanan yang diterima oleh konsumen sendiri tidaklah mudah. Sehingga perusahaan harus memaksimalkan kegiatan pelayanan ke arah yang lebih berkualitas untuk memaksimalkan keinginan pelanggan.

Dengan keluhan yang yang dihadapi PT. Jinde Grup Indonesia seperti jaringan tidak stabil, kecepatan internet lambat, pelayanan yang kurang ramah hingga lambatnya penanganan jika terjadi masalah. Yang mana dapat diketahui dengan jelas apa yang diharapkan oleh pelanggan belum terpenuhi. Serta cara untuk melakukan peningkatan kualitas pelayanan tersebut. Untuk mengukur kualitas pelayanan dapat dilihat dengan membandingkan anatara harapan (expectation) dan performansi (perceived) pelanggan dari suatu layanan jasa yang telah didapatkan. Dengan metode Servqual dapat dilakukan perhitungan antara rata-rata kinerja (persepsi) dan skor rata-rata tingkat kepentingan (harapan) pelayanan untuk tiap dimensi Servqual, seperti Tangibles, Assurance, Reability, Responsivenes dan Emphaty.

Berdasarkan uraian latar belakang masalah dan judul di atas, maka dapat dirumuskan sebagai berikut : Bagaimana kualitas pelayanan yang diberikan PT. Jinde Grup Indonesia, atribut apa saja yang dipriotaskan dalam usulan perbaikan di PT. Jinde Grup Indonesia, bagaimana usulan dalam peningkatan kualitas pelayanan PT. Jinde Grup Indonesia.

\section{Kajian Teoritis}

Kepuasan pelanggan adalah "persepsi pelanggan harapannya telah terpenuhi atau terlampaui" (Tjiptono, 2002). Sedangkan menurut Kotler dan Amstrong mengungkapkanbahwa kepuasan pelanggan adalah "tingkatkan dimana kinerja anggapan produk sesuai dengan ekspektasi pembeli" (Kotler dkk, 2007).

\section{Service Quality}

Menurut (Tjiptono, 2002) kualitas adalah suatu kondisi dinamis yang memiliki suatu hubungan dengan produk, jasa, manusia, proses dan lingkungan yang melebihi suatu harapan. Menurut (Parasuraman, 1985) mengemukakan bahwa kualitas layanan atau service quality merupakan elemen kritis dari persepsi pelangan akan produk jasa yang diterimanya. Khususnya dalam sebuah produk yang murni di bidang jasa, service quality akan menjadi sebuah elemen lebih dominan dalam penilainan pelanggan. 


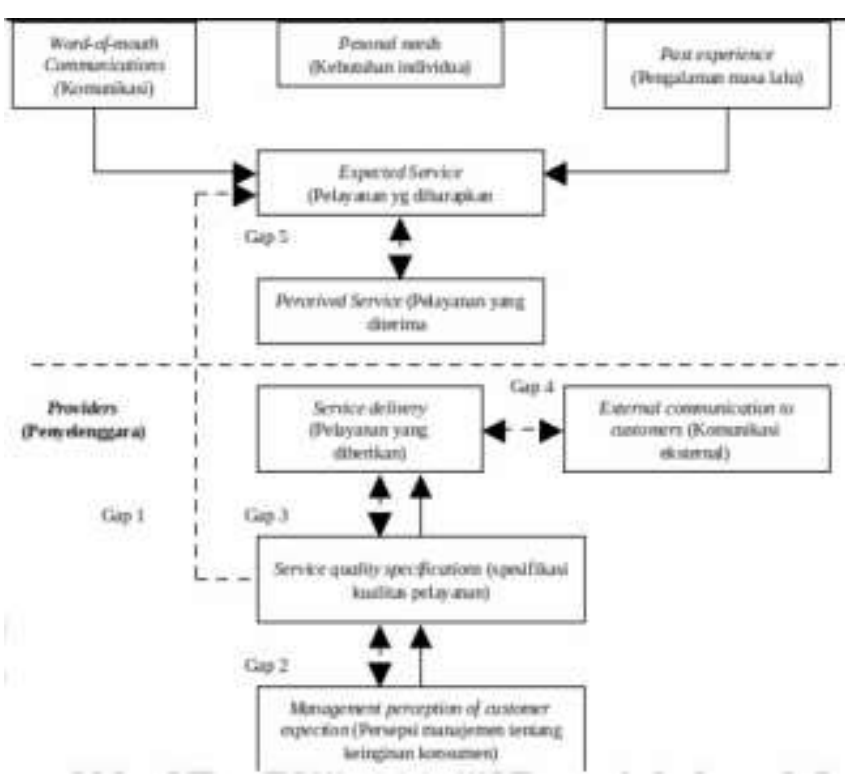

Gambar 2. Gap Model Kualitas Jasa

\section{Improvement Gap Analysis}

Improvement Gap Analysis merupakan metode yang memiliki kesamaan dengan metode Importance Performance Analysis, yaitu model analisis kuadran pada kualitas jasa. Improvement Gap Analysis (IGA) memadukan antara model Kano dengan metode Importance Performance Analysis. Adanya kekurangan pada kedua metode dan model tersebut, Improvement Gap Analysis memadukannya dengan konsep yang berbeda unutk menilai suatu kualitas jasa. Pada metode ini tidak deperlukan suatu perusahaan pesaing guna menilai suatu kualitas jasa yang ditawarkan. Selain itu metode tersebut dapat menggambarkan bagaimana respon dari responden jika atribut penilaian yang ada dilakukan perbaikan atau improve (Picolo dkk, 2016).

Tedapat dua bagian pada kuesioner yang digunakan untuk mendapatkan data yang dibutuhkan (Tontini dkk, 2010) yaitu :

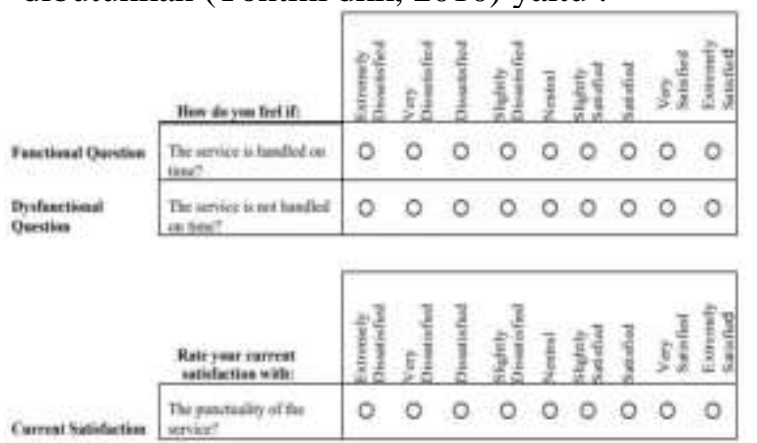

Gambar 3. Contoh Kuesioner IGA

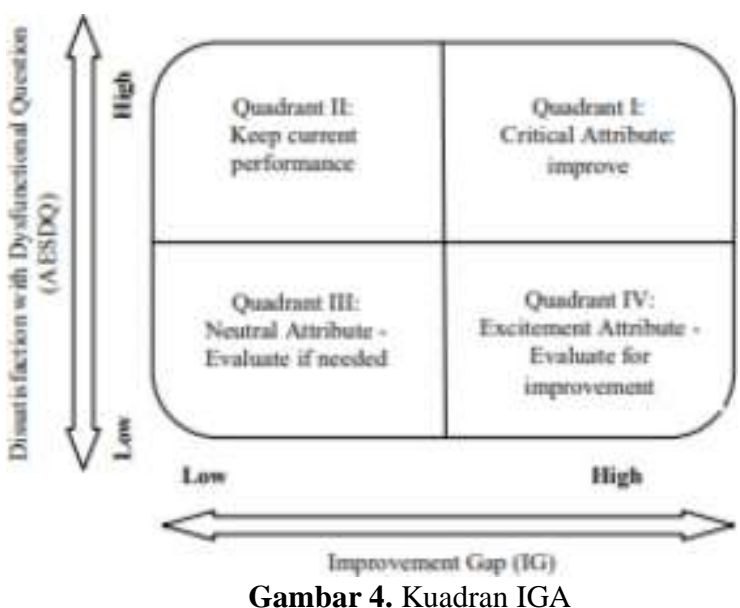

Keterangan:

Kuadran I

Atribut dengan nilai AG yang tinggi dan nilai ketidakpuasaan yang tinggi pada pertanyaan disfungsional (AESDQ) dan dianggap penting untuk ditingkatkan.

Kuadran II

Atribut dengan nilai EASDQ yang tinggi dan nilai IG yang rendah. Penjelasannya bahwa atribut tersebut tidak perlu ditingkatkan lebih lanjut, tetapi perusahaan harus berhati-hati agar tidak menurunkan performansi dari atribut ini yang dapat menyebabkan ketidakpuasaan konsumen yang besar.

Kuadran III

Atribut dengan nilai IG yang rendah dan memiliki ketidakpuasaan yang rendah terhadapat pertanyaan disfungsional (AESDQ) dan dinggap atribut netral. Penjelasannya adalah bahwa ada atau tidaknya atribut tersebur tidak akan mempengaruhi kepuasaan atau ketidakpuasaa konsumen.

Kuadran IV

Atribut dengan nilai IG yang tinggi dan nilai ketidakpuasaan yang rendah pada pertanyaan disfungsional (AESDQ) dianggap atribut excitement. Dengan penjelasan bahwa atribut tersebut tidak akan mempengaruhi ketidakpuasaan konsumen yang besar bila tidak ada, namun akan meningkatkan kepuasaan konsumen yang besar bila ada.

\section{METODOLOGI PENELITIAN}

Metodologi penelitian ini bertujuan untuk memudahkan dalam melakukan penelitian sehingga penelitian yang dilakukan dapat 
terstruktur dengan baik. Agar di dalam penyusunan didapatkan data yang objektif dan ilmiah, maka diperlukan cara atau langkahlangkah tertentu yang dapat dipakai sebagai pedoman dalam menyelidiki dan membahas persoalan yang dihadapi.

Objek pada penelitian ini di PT. Jinde Grup Indonesia yang berlokasi di Jalan Berlian Biru Kav. 45 No. 51 Pondok Permata Suci Kecamatan Manyar Kabupaten Gresik. Responden pada penelitian ini adalah masyarakat di wilayah Dusun Betiring Desa Banjarsari Kecamatan Cerme Kabupaten Gresik yang menggunakan jaringan My Rise. Dan penelitian ini dilakukan pada hari kerja.

Tabel 1. Kuisioner

\begin{tabular}{|c|c|}
\hline No & Atribut \\
\hline & Bukti Fisik (Tangible) \\
\hline 1 & $\begin{array}{l}\text { Peralatan yang mendukung layanan } \\
\text { berfungsi dengan baik }\end{array}$ \\
\hline 2 & Meimliki kantor yang nyaman \\
\hline 3 & Penapilan petugas rapi \\
\hline \multirow[t]{2}{*}{4} & Fasilitas kantor penyedia layanan nyaman \\
\hline & Keandalan (Reliability) \\
\hline 5 & Layanan diberikan tepat waktu \\
\hline 6 & Proses registrasi mudah dan cepat \\
\hline 7 & Akses layanan stabil \\
\hline 8 & Layanan sesuai kebutuhan pelanggan \\
\hline \multirow[t]{2}{*}{9} & $\begin{array}{l}\text { Harga yang diberikan sesuai } \\
\text { dengan yang dijanjikan }\end{array}$ \\
\hline & Daya Tanggap (Resposiveness) \\
\hline 10 & $\begin{array}{l}\text { Petugas layanan melayani keluhan dengan } \\
\text { cepat }\end{array}$ \\
\hline 11 & $\begin{array}{l}\text { Penyedia layanan memberikan kemudahan } \\
\text { dalam pelayanannya }\end{array}$ \\
\hline 12 & $\begin{array}{l}\text { Daya tanggap petugas layanan dalam } \\
\text { menjelaskan bagus }\end{array}$ \\
\hline \multirow[t]{2}{*}{13} & $\begin{array}{l}\text { Keluhan terhadap masalah layanan } \\
\text { diselesaikan sampai tuntas }\end{array}$ \\
\hline & Jaminan (Assurance) \\
\hline 14 & $\begin{array}{l}\text { Adanya pemberian ganti rugi apabla ada } \\
\text { kesalahan dalam pemasangan layanan }\end{array}$ \\
\hline 15 & $\begin{array}{l}\text { Pelanggan dengan mudah menyampaikan } \\
\text { keluhan jika terjadi suatu masalah }\end{array}$ \\
\hline 16 & Tidak ada gangguan pada sistem layanan \\
\hline \multirow[t]{2}{*}{17} & $\begin{array}{l}\text { Kemudahan dalam menghubungi petugas } \\
\text { layanan bila terjadi masalah }\end{array}$ \\
\hline & Empati (Empathy) \\
\hline 18 & Adanya garansi kepada pelanggan \\
\hline 19 & $\begin{array}{l}\text { Keramahan petugas layanan saat } \\
\text { melayani pelanggan }\end{array}$ \\
\hline
\end{tabular}

\begin{tabular}{|c|l|}
\cline { 2 - 3 } 20 & $\begin{array}{l}\text { Petugas layanan berkomunikasi dengan } \\
\text { pelanggan dengan cara yang } \\
\text { menyenangkan }\end{array}$ \\
\hline 21 & $\begin{array}{l}\text { Pelanggan dapat informasi apabila ada } \\
\text { layanan baru }\end{array}$ \\
\hline 22 & Tersedia tempat kritis dan saran \\
\hline
\end{tabular}
Sumber : Ulkhaq, 2017

Kerangka Peyelesaian Masalah

Penelitian ini dimulai dengan studi lapangan yaitu melihat langsung permasalahan yang terjadi seperti apa. Kemudian dilanjutkan ke studi literatur untuk mempelajari dasar-dasar netode yang akan digunakan dalam penelitian ini sebagai dasar untuk penyusunan kuesioner. Setelah hasil dari kiesioner didapatkan maka selanjutkan dilakukan penarikan kesimpulan dengan metode service quality dan improvement gap anslysis.

\section{HASIL DAN PEMBAHASAN} Analisis Service Quality (SERVQUAL)

Analisa kebutuhan konsumen berdasarkan tingkat kepuasan yang merupakan kesenjangan (GAP) antara persepsi/ kinerja dan harapan konsumen adalah suatu kebutuhan yang harus dikoreksi oleh pihak manajemen. Tingkat perbaikan diperoleh dari atribut yang bernilai negatif yang mengidentifikasikan keinginan konsumen yang belum terpenuhi. Sedangkan atribut layanan yang sudah bernilai positif mengidentifikasikan keinginan konsumen yang sudah terpenuhi. Untuk selengkapnya dapat dilihat pada tabel.

Tabel 2. GAP Servqual

\begin{tabular}{|c|l|c|}
\hline Kode & \multicolumn{1}{|c|}{ Atribut } & Gap \\
\hline Rel 3 & Akses layanan stabil & $-1,77$ \\
\hline Ass 3 & $\begin{array}{l}\text { Tidak ada gangguan pada } \\
\text { sistem pelayanan }\end{array}$ & $-1,45$ \\
\hline Rel 1 & Layanan diberikan tepat waktu & $-1,31$ \\
\hline Tg 3 & $\begin{array}{l}\text { Penampilan petugas rapi dan } \\
\text { menarik }\end{array}$ & $-1,29$ \\
\hline Res 1 & $\begin{array}{l}\text { Petugas layanan malayani } \\
\text { keluhan dengan cepat }\end{array}$ & $-1,29$ \\
\hline Emp 1 & $\begin{array}{l}\text { Adanya garansi kepada } \\
\text { pelanggan }\end{array}$ & $-1,28$ \\
\hline Res 2 & $\begin{array}{l}\text { Penyedia layanan memberikan } \\
\text { kemudahan dalam } \\
\text { pelayanannya }\end{array}$ & $-1,27$ \\
\hline Ass 1 & $\begin{array}{l}\text { Adanya pemberian ganti rugi } \\
\text { apabila ada kesalahan dalam } \\
\text { pemasangan layanan }\end{array}$ & $-1,25$ \\
\hline
\end{tabular}




\begin{tabular}{|l|l|l|}
\hline Ass 2 & $\begin{array}{l}\text { Pelanggan dengan mudah } \\
\text { menyampaikan keluhan jika } \\
\text { terjadi suatu } \\
\text { masalah }\end{array}$ & $-1,25$ \\
\hline Tg 2 & $\begin{array}{l}\text { Penyedia layanan mempunyai } \\
\text { kantor yang nyaman }\end{array}$ & $-1,25$ \\
\hline Res 3 & $\begin{array}{l}\text { Daya tanggap petugas layanan } \\
\text { dalam menjelaskan bagus }\end{array}$ & $-1,25$ \\
\hline Emp 5 & Tersedia tempat kritik dan saran & $-1,25$ \\
\hline Ass 4 & $\begin{array}{l}\text { Kemudahan dalam } \\
\text { menghubungi petugas layanan } \\
\text { bila terjadi } \\
\text { masalah }\end{array}$ & $-1,24$ \\
\hline Emp 2 & $\begin{array}{l}\text { Keramahan petugas layanan } \\
\text { saat melayani pelanggan }\end{array}$ & $-1,23$ \\
\hline Tg 4 & $\begin{array}{l}\text { Fasilitas kantor penyedia } \\
\text { layanan nyaman }\end{array}$ & $-1,22$ \\
\hline Rel 4 & $\begin{array}{l}\text { Layanan sesuai dengan } \\
\text { kebutuhan pelanggan }\end{array}$ & $-1,22$ \\
\hline
\end{tabular}

Analisis Impromevent Gap Analysis (IGA)

Dari pengolahan data menggukan Improvement Gap Analysis yang selanjutnya diolah dengan menggukan diagram kartesius terdapat sepuluh atribut yang masuk ke dalam kuadran I, dua atribut yang masuk kuadran II, tujuh atribut yang masuk dalam kuadran III dan tiga atribut yang masuk dalam kuadran IV.

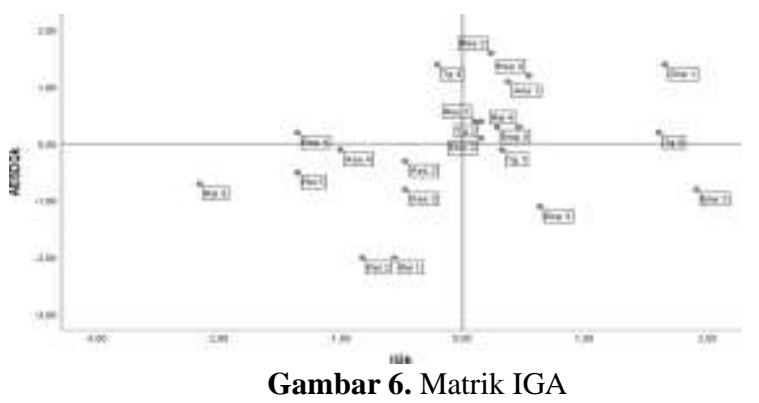

Usulan Perbaikan

Tavel 3. Usulan Perbaikan

\begin{tabular}{|c|c|l|}
\hline No & Atribut & \multicolumn{1}{c|}{$\begin{array}{c}\text { Usulan } \\
\text { Perbaikan }\end{array}$} \\
\hline 1 & $\begin{array}{l}\text { Adanya garansi } \\
\text { kepada } \\
\text { pelanggan }\end{array}$ & $\begin{array}{l}\text { PT. Jinde Grup Indonesia } \\
\text { sebaiknya memberikan } \\
\text { garansi kepada pelanggan } \\
\text { apabila terjadi kerusakan } \\
\text { yang berasal bukan dari } \\
\text { pemakaian pelanggan }\end{array}$ \\
\hline 2 & $\begin{array}{l}\text { Penampilan } \\
\text { petugas rapi dan } \\
\text { Menarik }\end{array}$ & $\begin{array}{l}\text { Dibuatkan SOP terkait } \\
\text { masalah penggunan } \\
\text { seragam yang baik }\end{array}$ \\
\hline
\end{tabular}

\begin{tabular}{|c|l|l|}
\hline 3 & $\begin{array}{l}\text { Daya } \\
\text { tanggap } \\
\text { petugas } \\
\text { layanan } \\
\text { dalam } \\
\text { menjelaskan } \\
\text { bagus }\end{array}$ & $\begin{array}{l}\text { Dilakukan pelatihan secara } \\
\text { berkala agar petugas } \\
\text { layanan tetap memiliki } \\
\text { informasi yang } \\
\text { mumpuni }\end{array}$ \\
\hline 4 & $\begin{array}{l}\text { Penyedia } \\
\text { layanan } \\
\text { memberikan } \\
\text { kemudahan } \\
\text { dalam } \\
\text { pelayanannya }\end{array}$ & $\begin{array}{l}\text { Sebaiknya PT. Jinde } \\
\text { Grup Indonesia } \\
\text { menyediakan Customer } \\
\text { Service yang dapat } \\
\text { menjawab keluhan pelanggan }\end{array}$ \\
\hline
\end{tabular}

\section{KESIMPULAN}

Dari hasil di atas dapat diketahui bahwa kualitas pelayanan yang diberikan oleh PT. Jinde Grup Indonesia masih kurang memuaskan. Dapat dilihat dari tingginya gap tiap atribut pelayanan dalam analisis service quality yang menunjukkan bahwa kualitas pelayanan yang diberikan masih jauh dari apa yang diharapkan oleh pelanggan. Untuk mengatasi gap tersebut maka PT. Jinde Grup Indonesia harus melakukan peningkatan kualitas pelayanannya yang menjadi prioritas dalam kuadran 1 yang didapatkan dari dengan metode improvement gap analysis.

\section{Saran}

Saran yang diberikan untuk PT. Jinde Grup Indonesia harus memperbaiki kinerja atributatribut jasa yang dianggap penting oleh pelanggan guna meningkatkan indeks kepuasaan pelanggan terutama yang berada di kuadran I yang berjumlah 10 atribut. Sehingga pelanggan tidak merasa kecewa terhadap pelayanan yang diberikan oleh PT. Jinde Grup Indonesia. Dan PT. Jinde Grup Indonesia harus mempertahankan kinerja atributatribut kualitas jasa yang dianggap penting dan berkinerja baik oleh pelanggan terutama di kuadran IV, sehingga pelanggan merasa puasa terhadap pelayanan yang diberikan PT. Jinde Grup Indonesia. Untuk pengujian berikutnya sebaiknya menggunakan metode lain untuk mengetahui output dari metode tersebut.

\section{DAFTAR PUSTAKA}

Alimansyah., Lipneldi., Dian, F. (2017). Analisis Tingkat Kepuasan Pelanggan Indihome PT. Telkom Kota Bengkulu. Jurnal Ilmiah Dinamika Sosial. Vol 1 No 2

Djarwanto, PS. (1994). Pokok-Pokok Analisis Laporan Keuangan. BPFE, Cetakan I, Yogjakarta.

Hakim, L., \& Sari, M. R. (2018). Analisis Tingkat Kepuasaan Pelanggan Terhadap Pelayanan PT. 
Tiki Lubuk Linggau Menggunakan Metode Servqual. Jusim, Vol 3, No 2.

Hartanto, Edwin. (2017). Usulan Perbaikan Kualitas Layanan Hotel X Dengan Metode SERVQUAL dan IGA. Irawan, H. (2003). Membedah Strategi Kepuasam Pelanggan. Jakarta: PT. Gramedia.

Kesumayansyah, H, \& Yuwono, M. A. (2014). Analisis Kepuasan Pelanggan Sebagai Upaya Peningkatan Kualitas Pelayanan Di SF Digital Photo Service. Analisis Kepuasan Pelanggan, Jurnal Sinergi Mercubuana, Vol19, No 1.

Kotler, P., \& Keller, K. (2007). Manajemen Pemasaran. Edisi 1.

Kurniawan, A. H. (2013). Analisis Kepuasan Pelanggan Dan Kepentingan Pelanggan Terhadap Kinerja Pelayanan Di PT. Greatway Engineering Service Dengan Metode Servqual. Matrik UMG, Vol 13, No 2.

Kurniawan, Didik., Wardana, Wisnu., \& Ito, Nikko Agustino. (2016). Pengabungan Dua ISP Guna Menstabilkan Koneksi Internet Dengan Metode Failover. Universitas Lampung

Lupriyoadi, R, \& Hamdani (2006). Manajemen Pemasaran Jasa. Jakarta : Salemba Empat.

Marluthy, Ayu.\& Halilah, Ii (2019). Peran Kualitas Pelayanan Penyedia Internet Terhadap Kepuasaan Pelanggan. Politeknik Negeri Bandung

Martillia, J. A., \& James, J. C. (1997). Importance Performance Analysis. American Marketing Associantion.

Mintarto, Rudi., (2017). Analisi Kualitas Pelayanan Pada Ritel Dengan Pendekatan Retail Quality Scale (RSQS), Customer Satisfication Index (CSI) Dan Improvement Gap Analysis (IGA). Universitas Islam Indonesia.

Muttaqin, Fadhlan., Hidayat, Rahmat. (2018). Analisis Tingkat Kepuasan Pelanggan Indihome pada Generasi Z di Kota Bandung 2018. Universitas Telkom.

Nurmalasari. (2014). Pengaruh Kualitas Pelayanan Dan Citra Terhadap Kepuasaan Pelanggan Mahasiswa Pada Akademi Kebidanan Aisiyah Pontianak. Khatulistiwa Informatika, Vol 2 No 2.

Parasuraman, Zeithaml, V. A., \& Berry, L. L. (1996). Reassesment of Expectation as a Comparasion Standart in Measure Service Quality : Impllication for Future Research. Journal of Marketing, Vol 58.

Putra, Cahya. (2019). Analisis Pengukuran Tingkat Kepuasan Pelayanan Terhadap Kepuasan Pelanggan Dengan Metode Service Quality (Servqual) Yang diintergrasikan Dengan
Metode Importance Performance Analysis (IPA). Universitas Islam Indonesia.

Risky, Muhammad Faisol. (2020). Analisis Kepuasan Pelanggan Menggunakan Metode Service Quality dan Importance Performance Analysis (Studi Kasus Pelayanan PDAM Giri Tirta Unit Suci. UniversitasMuhammadiyah Gresik.

Setyawan, W., Sutoni, A., \& Nashrun, Z. E. (2017). Analisis Kepuasan Pelanggan Terhadap Kualitas Pelayanan Menggunakan Metode Service Quality Dan Importance Performance Analysis (Studi Kasus Di Kantor PDAM Kabupaten Cianjur). Industrial Servicess. Vol 3, No 1a.

Singaribun, M. (2006). Metode Penelitian Survei. Jakarta. LP3ES. Suiyono. (2003). Metode Penelitian Administrasi. Bandung : Alfabeta.

Tan, K. C., \& Pawitra, T. A. (2001). Integrating Servqual And Kano's Model Into QFD for Service Excellence development. Managing Service Quality. Vol 11, No 6.

Tjiptono, F. (2002). Strategi Pemasaran. Jogjakarta : Andi.

Tjiptono, F., \& Chandra, G. (2011). Servqual And Satification. Yogjakarta : Andi, Edisi 3.

Tontini, G. \& Picolo, J. D. (2010). Improvement Gap Analysisi. Managing Service Quality. 20(6). 565-584. Ulkhaq, M. M., Barus M. P. Br. (2017). Analisis Kepuasan Pelanggan dengan Menggunakan SERVQUAL : Studi Kasus Layanan Indihome PT. Telekomunikasi Indonesia Tbk, Regional 1 Sumatera. Sistem dan Manajemen Industri, Vol a No 2.

Umar, Husein. (2001). Merode Penelitian dan Aplikasi dalam Pemasaran. Jakarta : PT. Gramedia Pustaka Umum. Wijaya, R., Lokajaya, I. N., \& Khoiroh, S. M. (2018) Analisis Kepuasan Pelanggan Denagan Metode Servqual dan peningkatan Performa Analisis (IPA) Di CV. Erdy Service Surabaya. Dinamika Manajemen, Vol 6, No3

Winanda, A. P., \& Sriyanto. (2015). Analisis Kualitas pelayanan Restoran Cepat Saji Dengan Metode Servqual (Service Quality) Dan IPA (Importance Perfrormance Analysis) Studi Kasus Restoran Olive Fried Chiken, Fokus Manajemen Bisnis Vol 5, No 2.

Winarno, H., \& Absor, T. (2018). Analisis Kualitas Pelayanan Dengan Metode Service Quality (Servqual) dan Importance Performance Analysis (IPA) Pada PT Media Purnama Engginering. Manajemen Industri Dan Logistik, 
E -ISSN : 2746-0835

Volume 2 No 2

JUSTI (Jurnal Sistem Dan Teknik Industri)

Vol 1, No 2.

Wulan, S. (2011). Analisis Kualitas Pelayanan Terhadap Kepuasaan Pelanggan Pada PT.

Perusaaan Lstrik Negara (Persero) Cabang

Tanjungkarang. Manajemen Dan Bisnis, Vol 1, No 2. 